Diabetologia $10,509-520(1974)$

() by Springer-Verlag 1974

\title{
Studies in the Diabetic Chinese Hamster: Electron Microscopy of Pancreatic Islets*
}

\author{
A. A. Like, G.C. Gerritsen, W. E. Dulin, and P. Gaudreau \\ Elliott P. Joslin Research Laboratory, Joslin Diabetes Foundation, Inc., Department of Pathology, Peter Bent \\ Brigham Hospital, Harvard Medical School, Boston, Mass., and the Upjohn Company, Kalamazoo, Michigan.
}

Summary. Electron microscopic studies were performed on pancreatic islets of normal, genetic, nondiabetic Chinese hamsters and of diabetic animals of all degrees of severity. The ultrastructural appearance of the islets of normal hamsters did not differ from that of normal rats and mice. The islets of the profoundly diabetic animals could be distinguished because of the magnitude of beta cell glycogen infiltration, frequency of beta cell necrosis and decreased number of surviving beta cells. Islets of hamsters with spontaneous remission from diabetes contained increased numbers of hyperfunctioning beta cells. Surviving beta cells of all diabetic hamsters revealed ultrastructural evidence of enhanced insulin synthesis and secretion but revealed no evidence to suggest that they were insensitive to physiological stimuli or incapable of insulin synthesis. Spontaneous remission among diabetic Chinese hamsters could thus be explained, in part, on the basis of enhanced beta cell replication resulting in an increased insulin synthetic capacity.

Key words: Chineso hamster, Cricetulus griseus, spontaneous diabetes, pancreatic islets, islets of Langerhans, beta cell necrosis, electron microscopy.
In this report we will present the results of ultrastructural studies of the pancreatic islets of normal and diabetic Chinese hamsters at the various stages of the syndrome. A companion paper [1] in this issue contains an account of the light microscopic and autoradiographic findings, as well as a brief summary of the syndrome and of the physiological data collected. during the investigations.

The electron microscopic study was initiated primarily to examine the pancreatic beta cells of hamsters that had undergone spontaneous remission from diabetes and of animals with an erratic syndrome. In so doing, special emphasis was directed towards answering the following questions: 1 . What is the morphologic basis for the physiological evidence of increased insulin synthesis among hamsters in remission [1].2. Are the beta cells of animals with an erratic syndrome or of those in remission ultrastructurally unique? Can they be differentiated from beta cells of more profoundly diabetic hamsters?

In order to address ourselves to these questions, it was necessary to examine the pancreatic islets of ketotic and non-ketotic hamsters as well as of animals in remission and with an erratic syndrome. Hence, we were afforded the opportunity to review and if appropriate confirm the findings of earlier investigators $[2,3,4]$ while taking advantage of improved methods of fixation and embedding.

\section{Materials and Methods}

For data concerning the source of animals, diet, technique of blood glucose and plasma immunoreactive

* Supported in part by USPHS Grants AM-15193, K4-AM-7394, AM05077, the Joslin Diabetes Foundation, Inc. and the Upjohn Company, Kalamazoo, Michigan. insulin analyses and the results of light microscopic examinations, the reader is referred to the accompanying article [1] in this issue.

Thirty-five diabetic hamsters and seven nondiabetic controls were used for the electron microscopic studies. The diabetics included animals with disease of all degrees of severity, including seven with recent onset, four with non-ketotic, four with ketotic, nine with erratic type diabetes and eleven animals with remission from diabetes. All diabetic hamsters and six of the seven normals were obtained from the Upjohn colony. Pancreata were fixed for electron microscopy by perfusion in fifteen animals and by immersion in twenty-seven animals using techniques previously reported [5] and thin sections were examined with RCA EMU 3G and Phillips 301 electron microscopes.

\section{Results \\ Normal Hamsters}

The overall organization and configuration of the pancreatic islets of nondiabetic hamsters could not be distinguished from that of other normal rodents studied in this laboratory [6]. The irregularly spherical collections of endocrine cells were organized by a network of fenestrated capillaries and scanty quantities of fibrocollagen into clusters and columns. Separated by an ample interstitial compartment which was preserved and somewhat accentuated by the perfusion fixation (Figs. 1, 8, 11, 14), the islet cells'were nevertheless in close and often intimate proximity with the intravascular compartment. The adjacent exocrine cells were in immediate juxtaposition with the well delineated islet periphery but excluded from the islet interior. Small non-myelinated nerves were frequently observed at the islet periphery, and numerous cholinergic and small numbers of adrenergic 
nerve endings noted within the islet where they appeared to be in close contact with the endocrine cells.

The Beta Cells located within the islet were relatively uniform in appearance (Figs. 1-3). Secretory storage granules were abundant and enclosed within spacious, granule-limiting membranes. Most granules appeared rounded when viewed in two dimensions, but were varied in size and electron density. The less electron-dense granules were usually larger and occupied a greater proportion of the enveloping sac than did the smaller more dense granules (Fig. 2). Crystalline appearing bar shaped beta granules were infrequently observed (Fig. 3) and resembled similar structures in the beta cells of mice and rats. In most well fixed beta cells of normoglycemic hamsters, the cysternae of the rough endoplasmic reticulum (RER) were inconspicuous, and

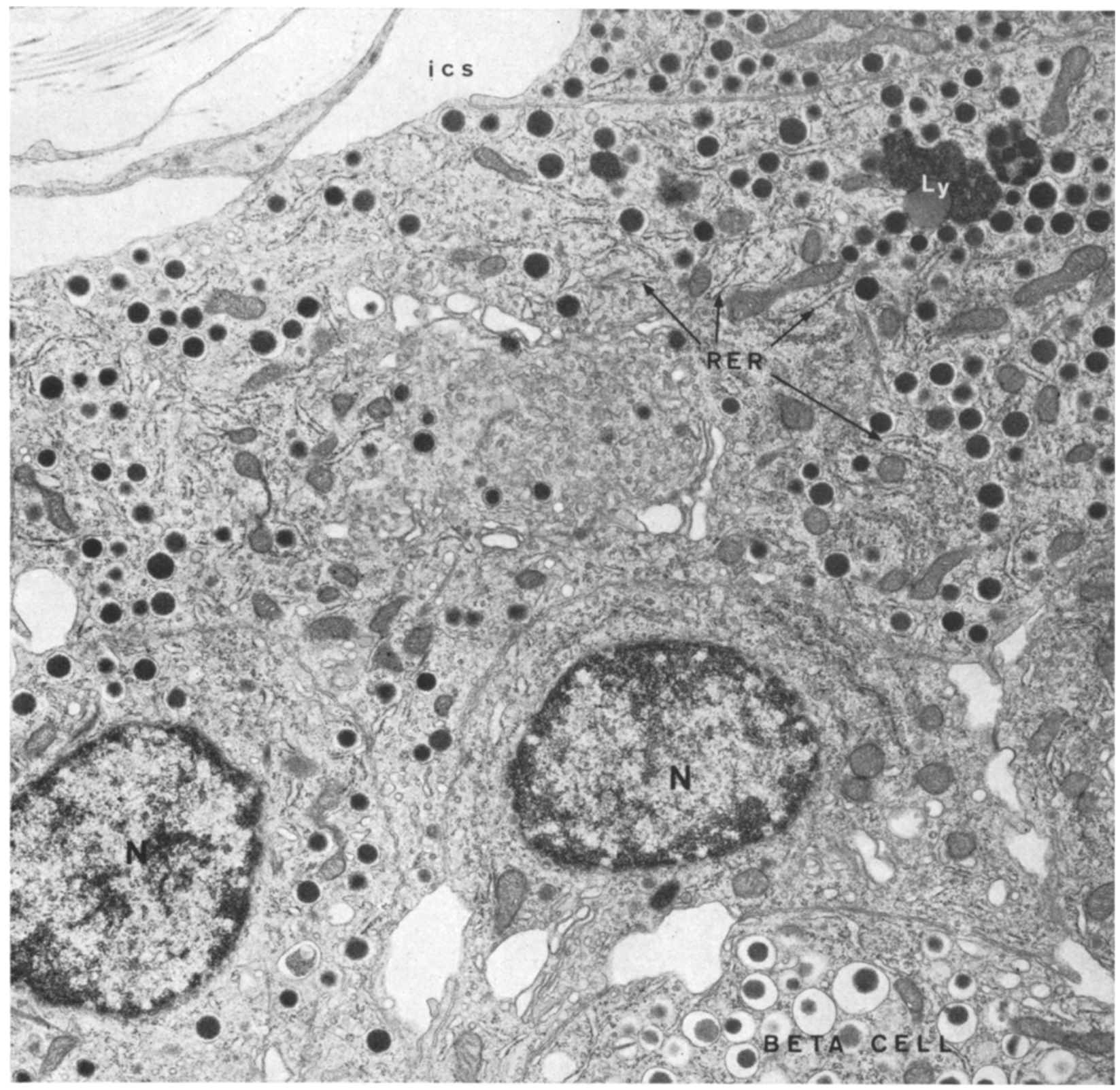

Fig. 1. Islet periphery normal. Several alpha and one beta cell (lower right) contain numerous secretory granules. Rough endoplasmic reticulum. (RER) is more prominent in alpha cells (see Figs. 2-4). Compare characteristic alpha cell lysosome (Ly) with that of beta cell in Fig. 9. $\mathrm{N}=$ nucleus, ics=intercellular space. Approximately $15,700 \times$ 


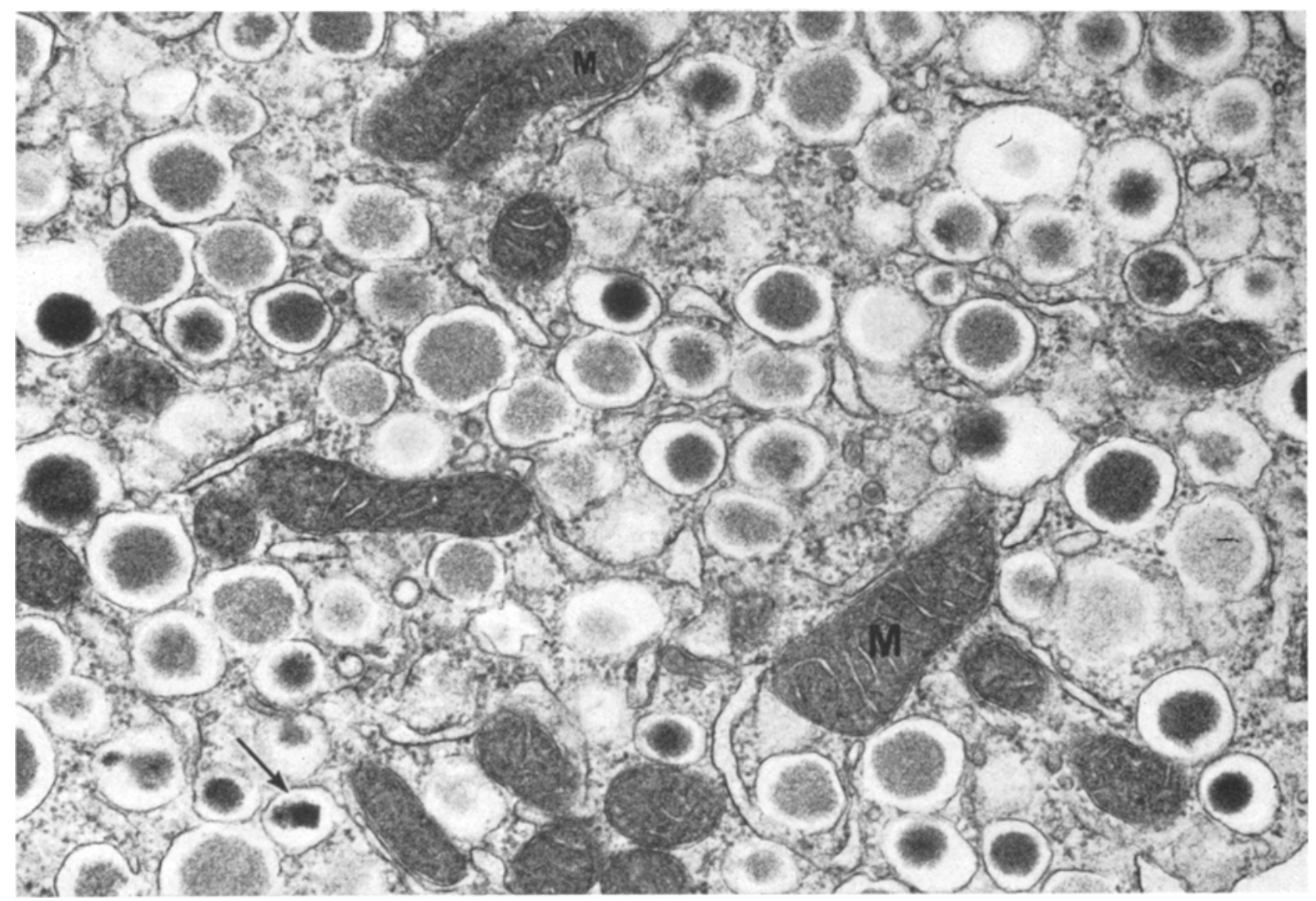

Fig. 2. Normal beta cell. Secretory granules are abundant and vary in appearance. Less electron-dense granules are larger and contain relatively indistinct borders. Irregular bar-shaped granule is indicated by arrow. Aldehyde fixative included trinitrocresol. $\mathrm{M}=$ mitochondrion. Approximately $34,300 \times$

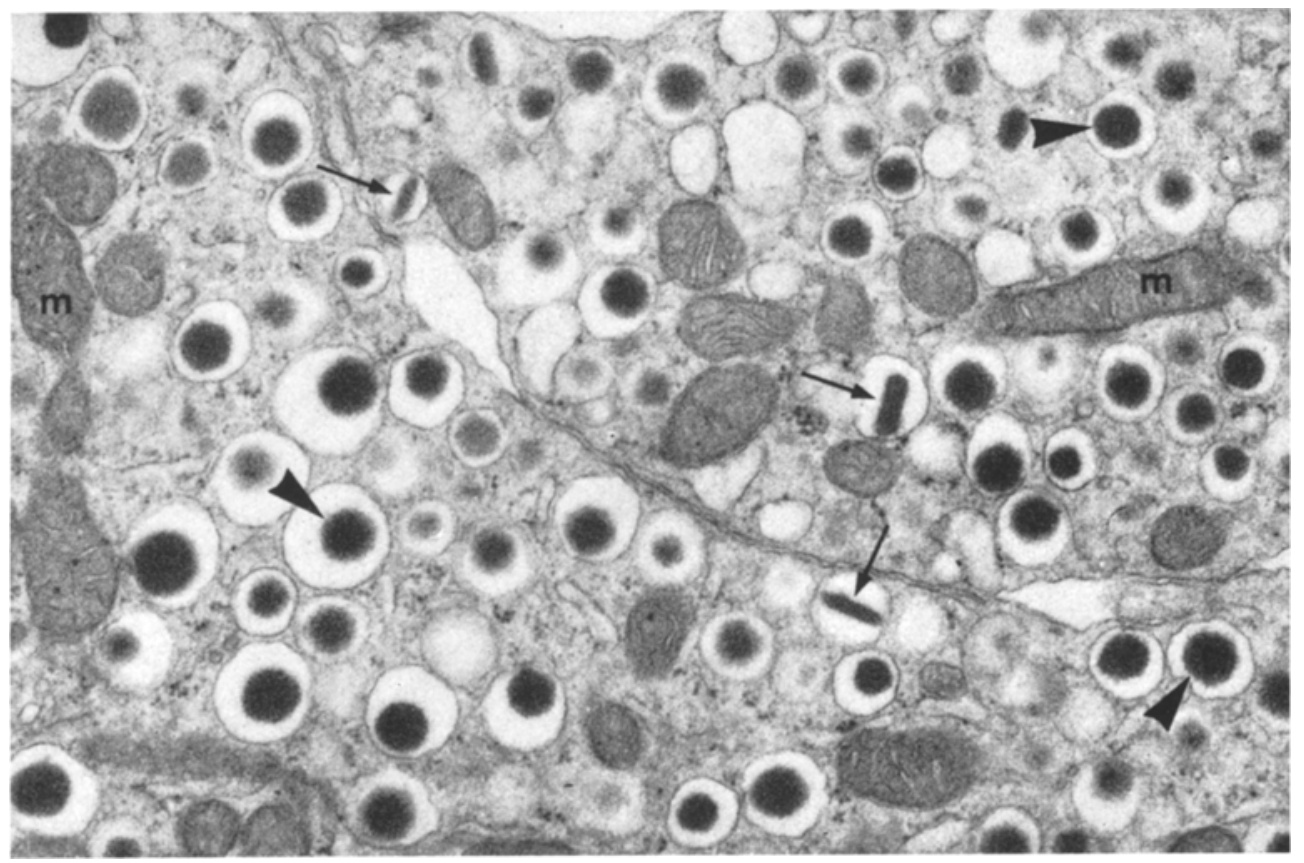

Fig. 3. Normal beta cell. Several bar-shaped secretory granules are indicated by arrows. Rounded granules (arrow heads) are more dense and less variable in appearance than in Fig. 2, perhaps due to the absence of trinitrocresol in fixative. Mitochondria (m) contain small dense granules. Approximately $22,330 \times$ 
golgi structures small. In the occasional cell with decreased numbers of secretory granules, the golgi structures were correspondingly larger (Fig. 4) and the RER more plentiful. Frequently, lysosomal structures were present within the beta cells. Characteristically composed of membrane-bound, rounded, vacuolated, electron lucent areas, as well as irregularly rounded aggregates of electron dense particulate material (Fig. 9), these structures were readily differentiated from their alpha cell counterparts (Fig. 1) [2]. Mitochondria were small and slender with moderate numbers of cristae mitochondriales and infrequent dense granules (Fig. 3).

The Alpha Cells were limited to the islet periphery in nondiabetic hamsters (Fig. 1), where they fre- quently but incompletely separated the underlying islet cells from the adjacent exocrine cells. The alpha secretory granules were somewhat larger and more electron-dense than beta granules and were contained within more tightly fitting granule limiting membranes (Figs. 1, 5). There was little variation in size and electron density of these granules, and crystallinelike forms were not recognized. Although the inner dense cores of the alpha secretory granules were more discrete than the cores of the beta granules, they merged with a finely particulate material that partially filled the surrounding spaces bounded by the granule limiting membranes, producing a "sun-burst" appearance (Fig. 5). In comparison with the beta cells, the RER and golgi components were more prominent

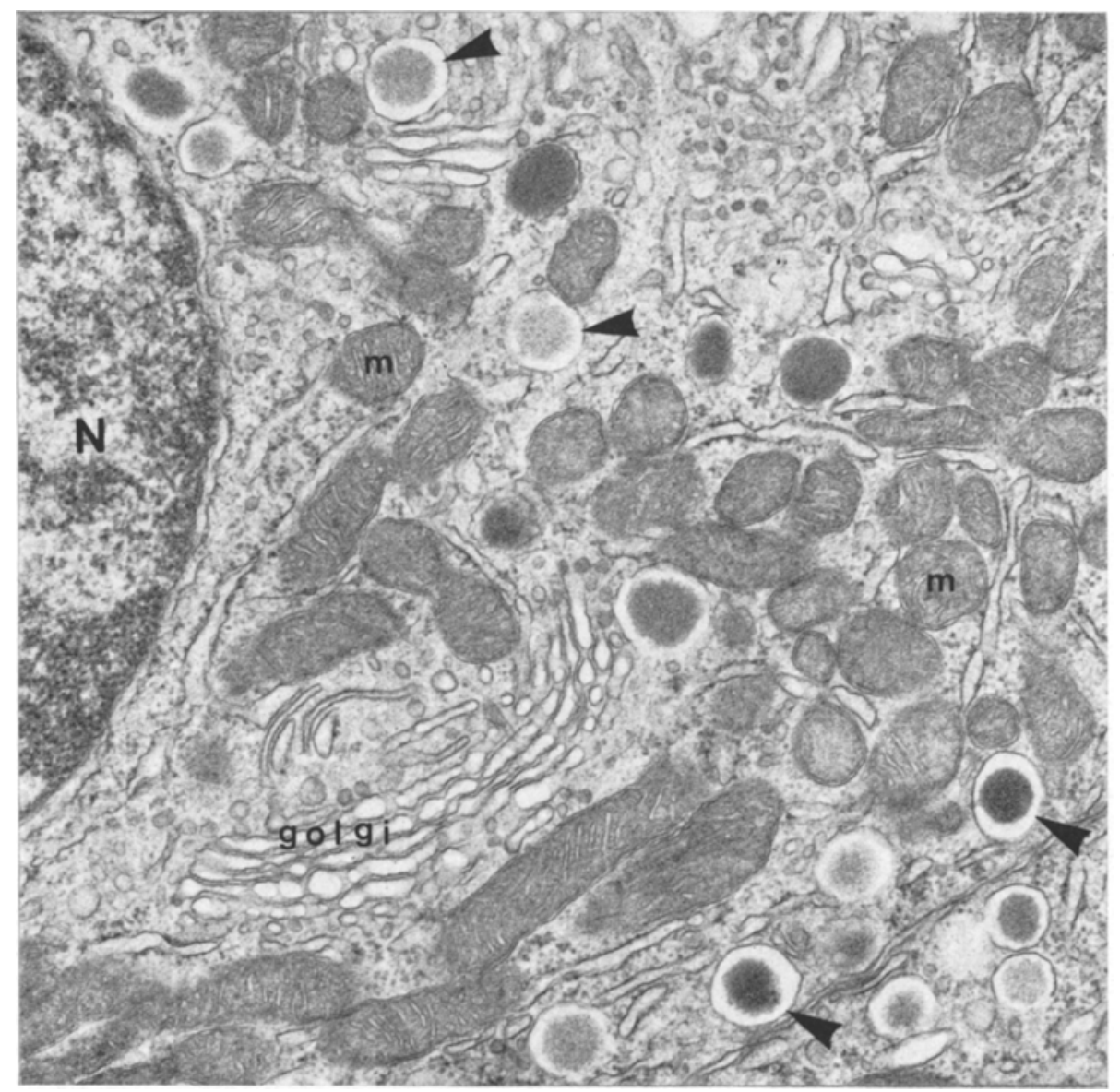

Fig. 4. Normal beta cell with proportionately fewer secretory granules (arrow heads) and a larger golgi. Mitochondria (m) and RER elements are more numerous. Approximately $25,410 \times$

Fig. 5. Alpha cell from hamster with erratic type diabetes showing perinuclear bundles of coarse microfilaments [13] (paired arrows). The granule limiting membranes are separated from the granule cores by a narrow space containing a fine particulate material which extends from the cores in a "sun burst" fashion. An autophagasome containing secretory granules (granulolysis) [4] is at the midportion of the lower margin of the micrograph. $\mathrm{np}=$ nuclear pores. Approximately 27,600 $\times$

Fig. 6. Normal delta cell with typical polymorphous secretory granules (arrow heads). $\mathrm{m}=$ mitochondria, rer $=$ rough endoplasmic reticulum. Approximately 54,400 $\times$ 


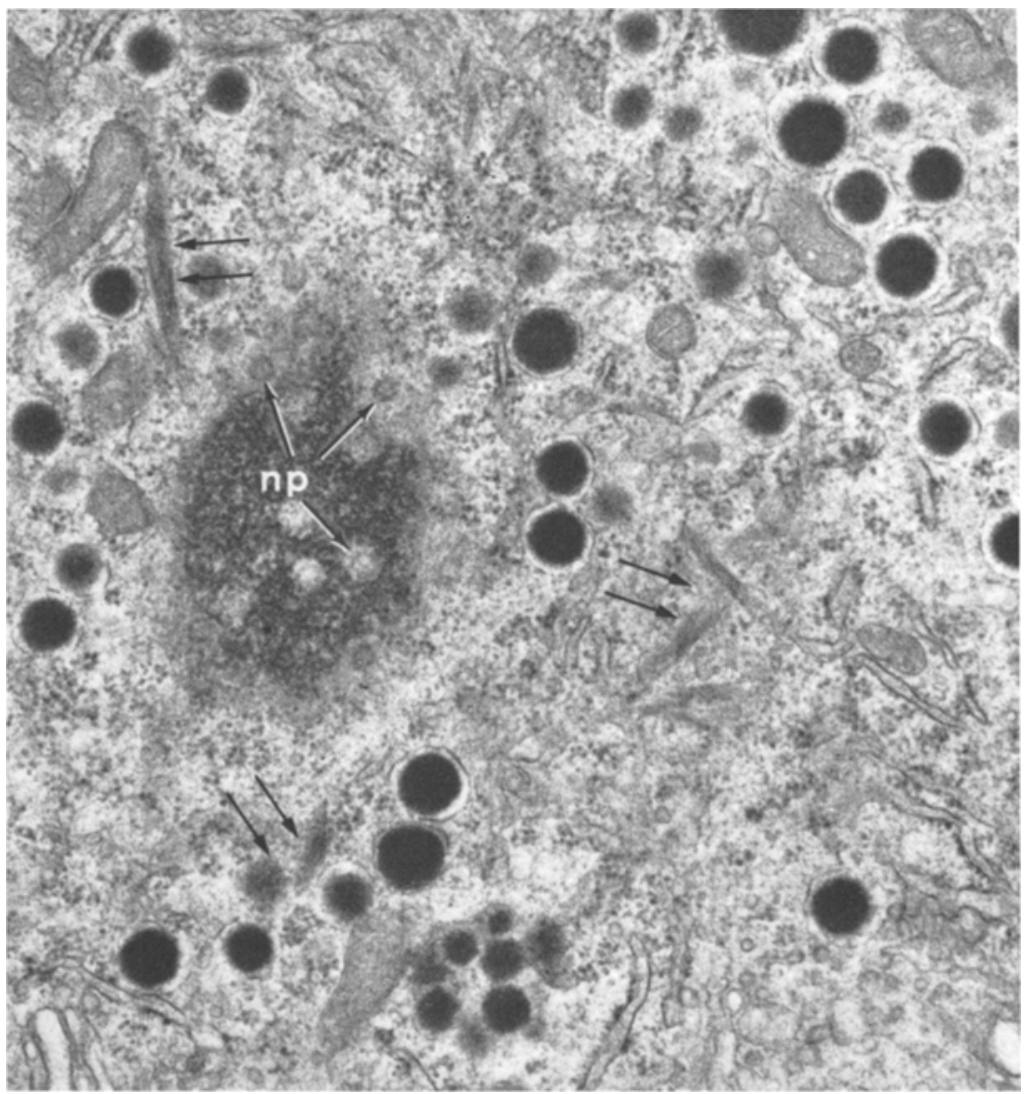

Fig. 5

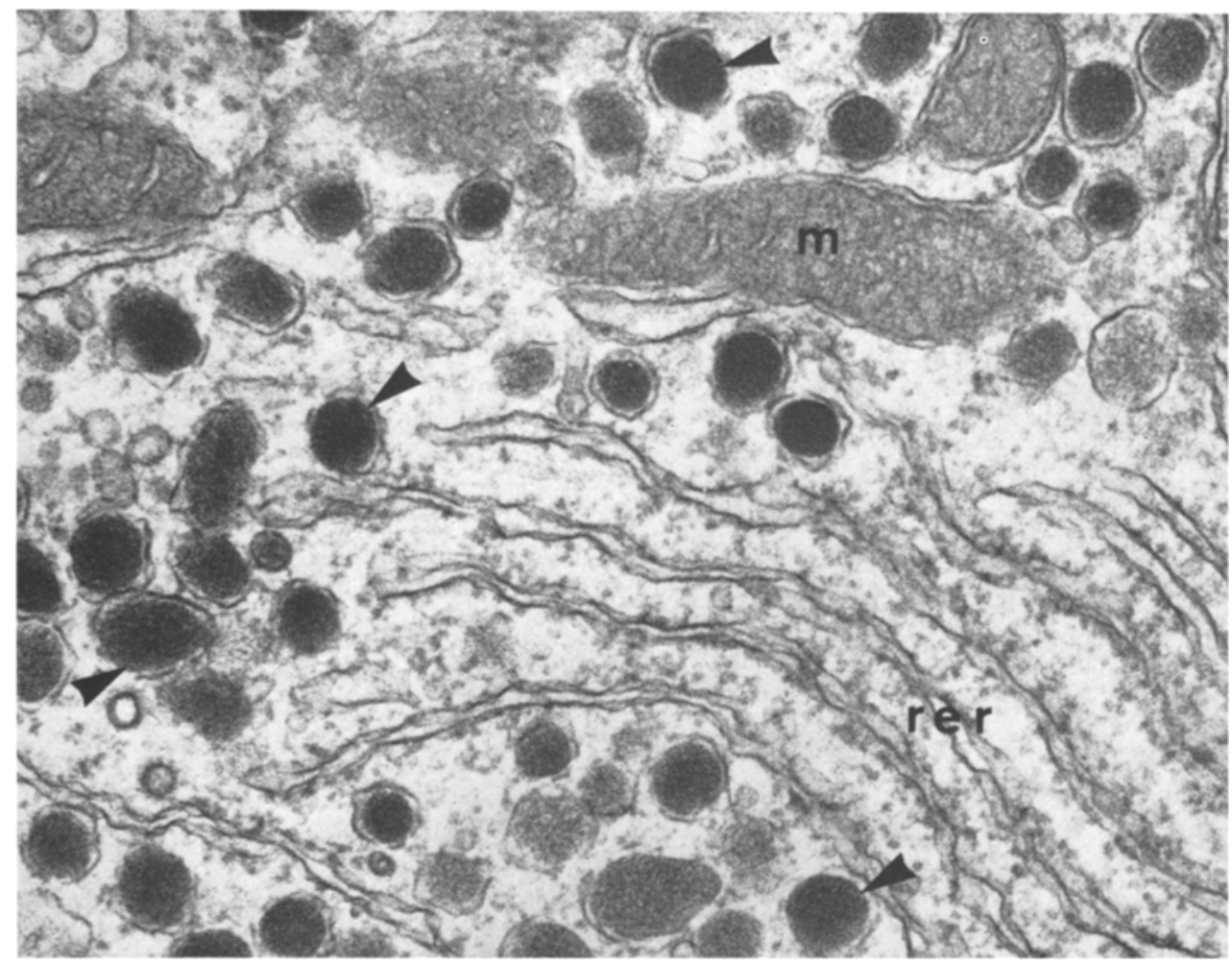

Fig. 6 
and the lysosomes more irregularly rounded and uniformly electron dense (Fig. 1). As also pointed out by Orci $e t a l$. in this issue [13], a unique feature of the subcellular structure of the alpha cell is the frequent presence in the perinuclear region of discrete bundles of coarse microfilaments, resembling "tonofilaments" (Fig. 5).

The Delta Cells were also limited to the islet periphery, where they were interspersed among the possibly gap and tight junctions as well were observed with considerable frequency and appeared to link the various endocrine cell types to each other (Fig. 7) and to the numerous intra islet nerve endings.

\section{Diabetic Hamsters}

Beta Cells. The most significant ultrastructural alterations were observed among the beta cells and

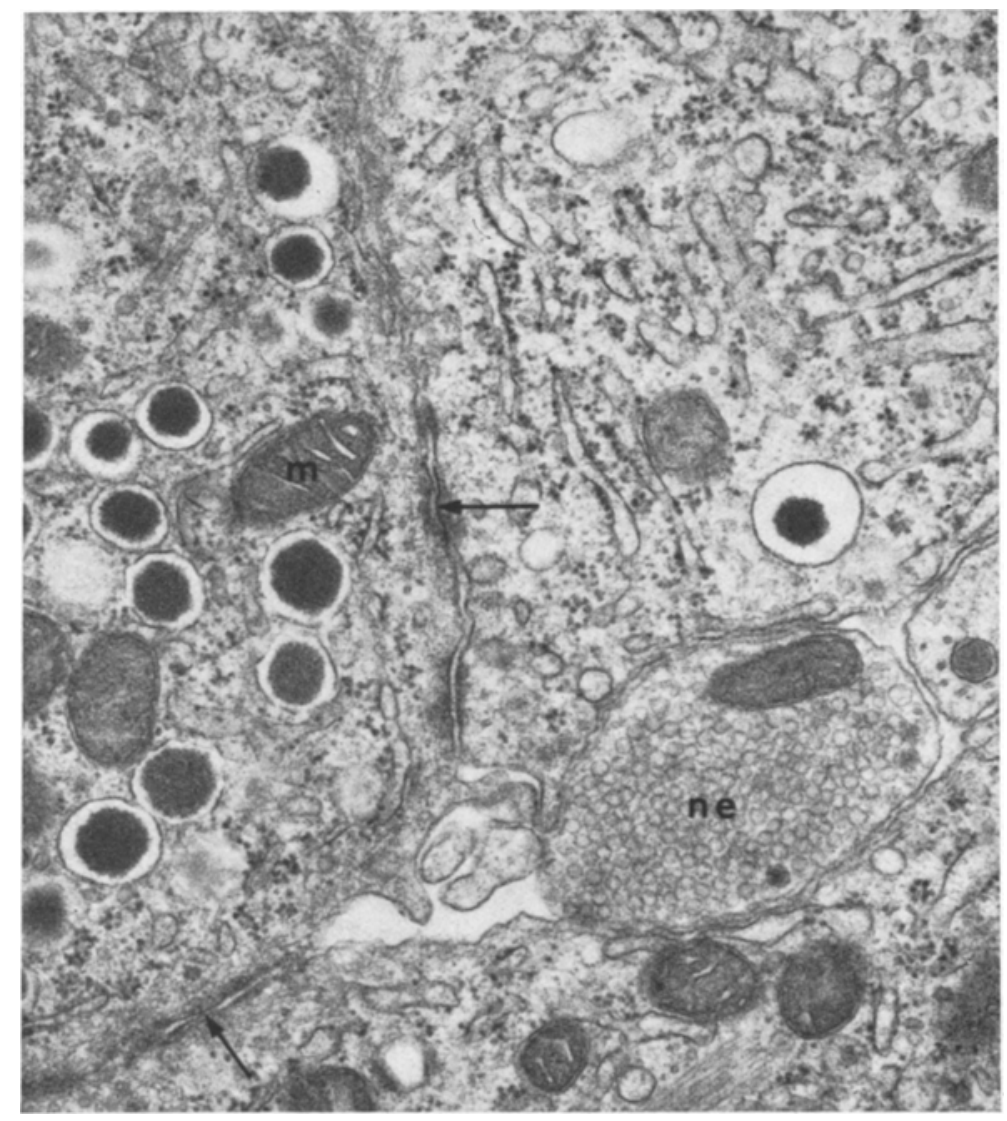

Fig. 7. Cholinergic nerve ending (ne) making intimate contact with two degranulated beta cells. Several junctional contacts, including presumptive gap junctions, (arrows) join the alpha cell (left side of micrograph) and beta cells. Approximately $30,000 \times$

alpha cells and the outermost beta cells. The unique delta secretory granules were slightly smaller than alpha granules, less electron-opaque and somewhat polymorphous in shape (Fig. 6). Although rounded forms predominated, oval or tear drop shaped granules were not infrequent and a very narrow space usually separated the secretory granules from the surrounding limiting membranes. The other cellular organelles were similar to those observed in the beta and alpha cells.

As previously described in the rat with sectional and freeze etch electron microscopy by Orci et al. [14], junctional complexes resembling desmosomes and included beta secretory granule depletion, a greatly expanded rough endoplasmic reticulum and an enlarged golgi (Figs. 8-12). Although the scope of these changes was variable from cell to cell, the overall magnitude of the alterations was similar among the various islets of an individual animal. Characteristically, the remaining secretory granules were smaller, less electron-dense and less distinctly delineated within the granule limiting membranes. Many appeared to be positioned at the cell periphery, in close proximity with the plasma membrane (Figs. $11,12)$. The mitochondria and lysosomes appeared to be unchanged in the intact beta cells. Cytoplasmic 
deposits of particulate glycogen were observed in diabetic animals where the extent of the deposition appeared to be directly proportional to the degree of hyperglycemia. Although occasional beta cells appeared to have been almost completely filled with glycogen (see ref. 2, Fig. 8), there was apparently no association of glycogen infiltration and cell necrosis. disruption of cytoplasmic continuity, "myelin figures" and, most characteristically, the presence of irregularly rounded, membrane enclosed, electron-dense masses (Fig. 13) [2]. When the dense masses were small, the surrounding membranes infrequently appeared to be studded with ribosomal particles (Fig. 13). Aggregates of glycogen were sometimes but not

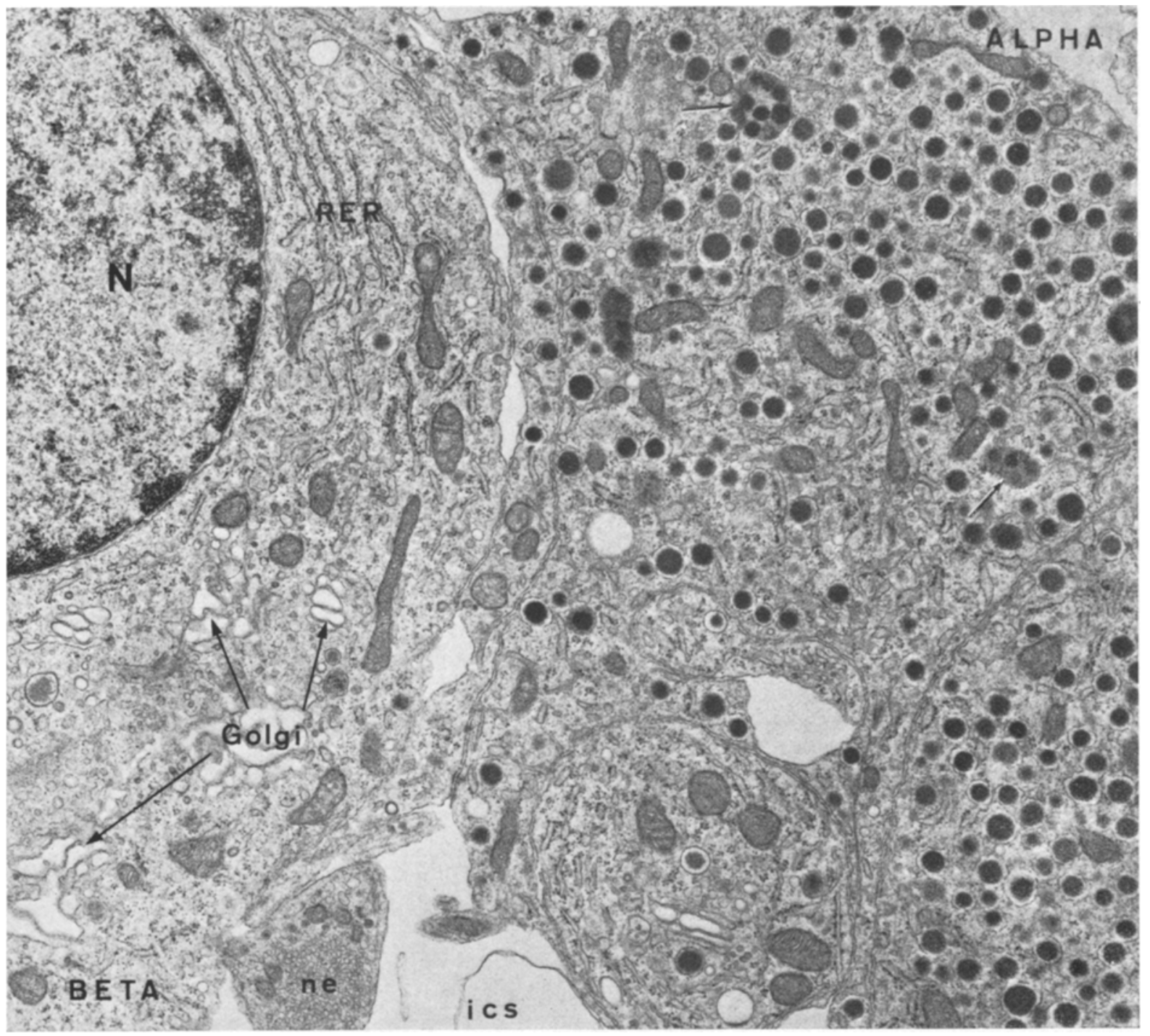

Fig. 8. Alpha and beta cells, moderately diabetic, nonketotic hamster. Beta secretory granules are diminished, rough endoplasmic reticulum (RER) increased and golgi enlarged. Alpha cell granulolysis (arrows) is noteworthy. ne=cholinergic nerve ending, ies =intercellular space, $\mathrm{N}=$ nucleus. Approximately $15,900 \times$

Necrotic Beta Cells. Beta cells undergoing cytoplasmic degeneration and necrosis were observed in animals with syndromes of varying severity. Although evidence of necrosis was more prevalent in severely diabetic and ketotic hamsters, the characteristic cellular changes were nevertheless identical and were also present in animals with the erratic syndrome and after spontaneous remission. The involved cells revealed always observed within the necrotic cells. Finally, fragments of necrotic debris were observed within presumed macrophages and within the interstitial tissue in association with increased numbers of collagen fibrils (Fig. 14).

Alpha Cells. The alpha cells of diabetic hamsters were altered predominantly by their relatively increased numbers and by changes in location within 
the islet, both best appreciated by light microscopy $[1,2,3]$. The only convincing subcellular alterations included the presence of increased numbers of lysosomes and of autophagasomes containing secretory granules (Fig. 8) [4]. There was no observed dilatation of the RER cysternae [4] and other cell organelles also appeared to be unchanged.

Delta Cells. The delta cells of the diabetic and normal hamsters could not be differentiated.

Although acinar and islet cells were frequently in intimate contact at the islet periphery, examples of mixed acinar-islet cells were not encountered. Furthermore, the acinar cells of normal and diabetic hamsters could not be differentiated.

\section{Discussion}

The findings reported above indicate that the islets of hamsters with diabetic syndromes of varying

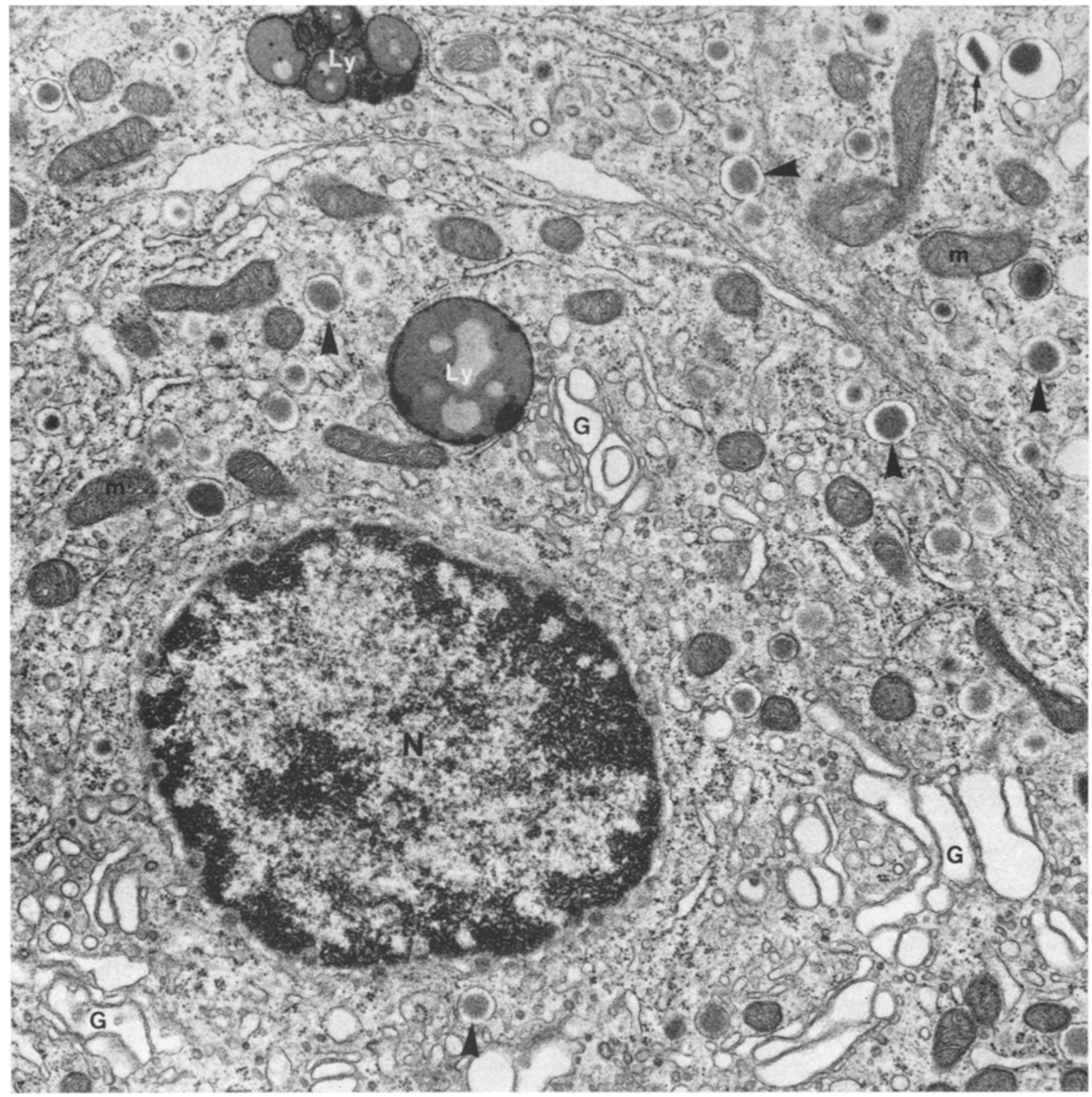

Fig. 9. Beta cells, moderately diabetic (non-ketotic) hamster. Secretory storage granules (arrow heads) are reduced in number and more variable in size. Golgi structures $(G)$ are enlarged and dispersed throughout the cell. Typical beta cell lysosomes (Ly) are visible. Crystalline-like granules (arrow) are less frequent in diabetic animals. Approximately $24,500 x$ 
severity could be differentiated from one another primarily by the presence and magnitude of beta cell glycogen infiltration, the frequency of beta cell necrosis and the number of surviving beta cells. Therefore, the islets of animals with the most severe syndromes (ketotic hamsters) contained the greatest number of necrotic beta cells, the smallest number of surviving beta cells, a greater degree of glycogen infiltration and the largest number of alpha cells per islet. The findings reported above also indicate that it was not possible to differentiate between the intact beta cells of the various hamsters, regardless of the morphological data to support the suggestion [12] that the beta cells are intrinsically insensitive to physiological stimuli or incapable of insulin synthesis; 2 . The morphologic basis for increased insulin synthesis among hamsters with remission from diabetes is the presence of increased numbers of hyperfunctioning beta cells; 3 . The sporadic appearance of spontaneous remission in the group of previously diabetic animals can probably best be explained on the basis of beta cell replication rather than as a result of physiological alterations leading to increased functional activity within the surviving beta cells; 4 . The beta cells of

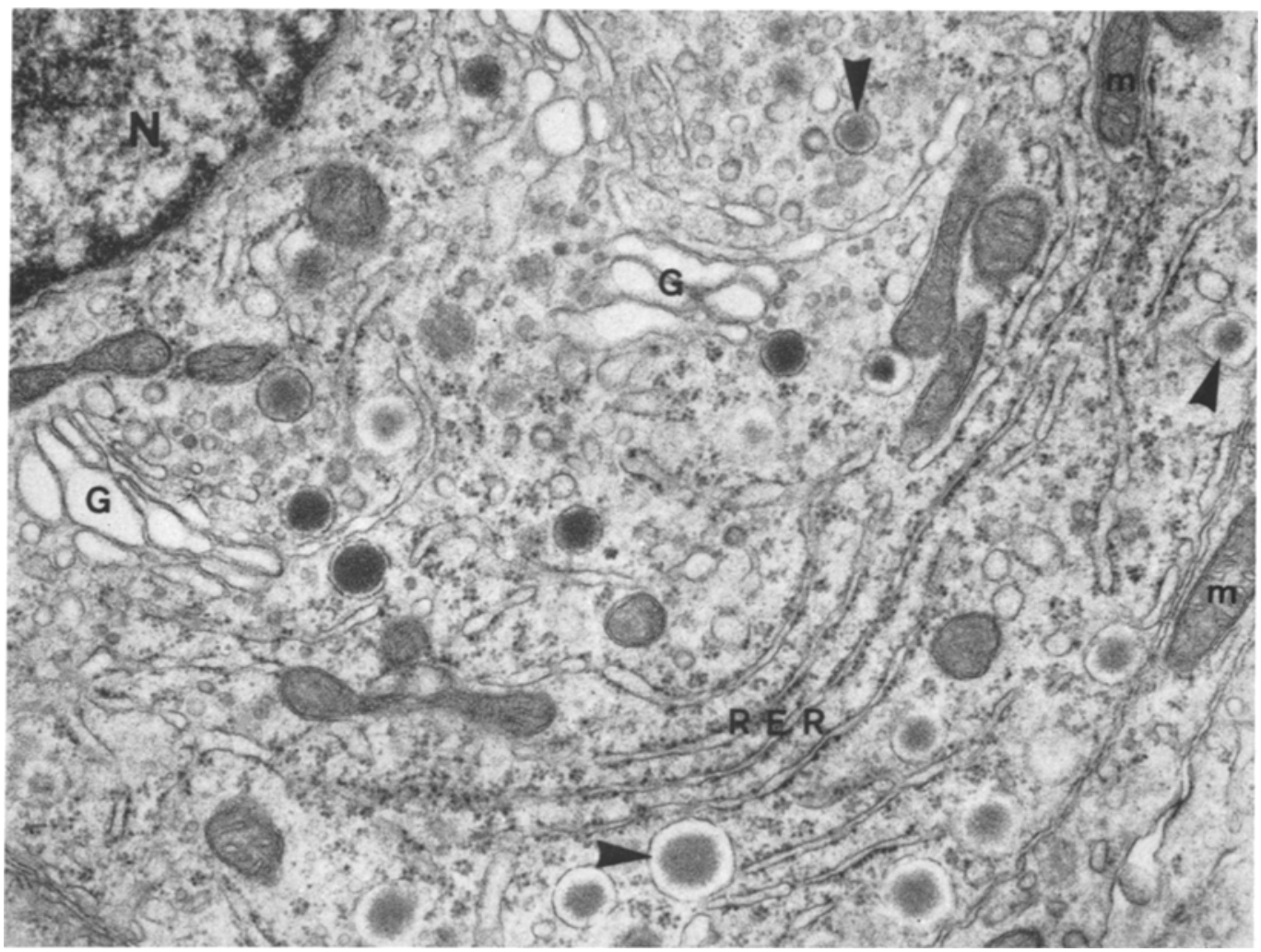

Fig. 10. Beta cells, diabetic hamster (erratic type). Secretory degranulation is associated with increased rough endoplasmic reticulum (RER) and enlarged golgi structures (G). Arrow heads indicate remaining beta granules. $\mathrm{m}=$ mitochondria, $\mathrm{N}=$ nucleus. Approximately $25,500 \times$

severity of the diabetic syndrome. All revealed ultrastructural evidence of enhanced insulin synthesis and secretion. An expanded RER, enlarged golgi structures and margination of remaining secretory granules were characteristically present, and, hence, these cells could not be differentiated from hyperfunctioning beta cells of other spontaneously diabetic animals $[6,7,8]$ or of animals with experimentally induced insulin hypersecretion $[9,10,11]$. The findings reported above are therefore consistent with the following observations: 1 . The severity of diabetes in the Chinese hamster is a function of reduced insulin synthesis and is directly related to the number of surviving functional beta cells [3]. There are no hamsters in remission and with the erratic syndrome are not structurally unique and cannot individually be differentiated from those of more severely diabetic hamsters; 5 . The physiological activity and morphologic appearance of the pancreatic islets of hamsters with the erratic syndrome vary greatly and cannot be objectively differentiated from that of the non-ketotic hamsters. However, it should be possible, eventually, to separate physiologically the non-ketotic hamsters into subgroups based upon a more precise evaluation of beta cell function. When this becomes feasible, it may also be possible to identify these subgroups morphologically and to identify the hamsters with the erratic syndrome as well. 
Fig. 11
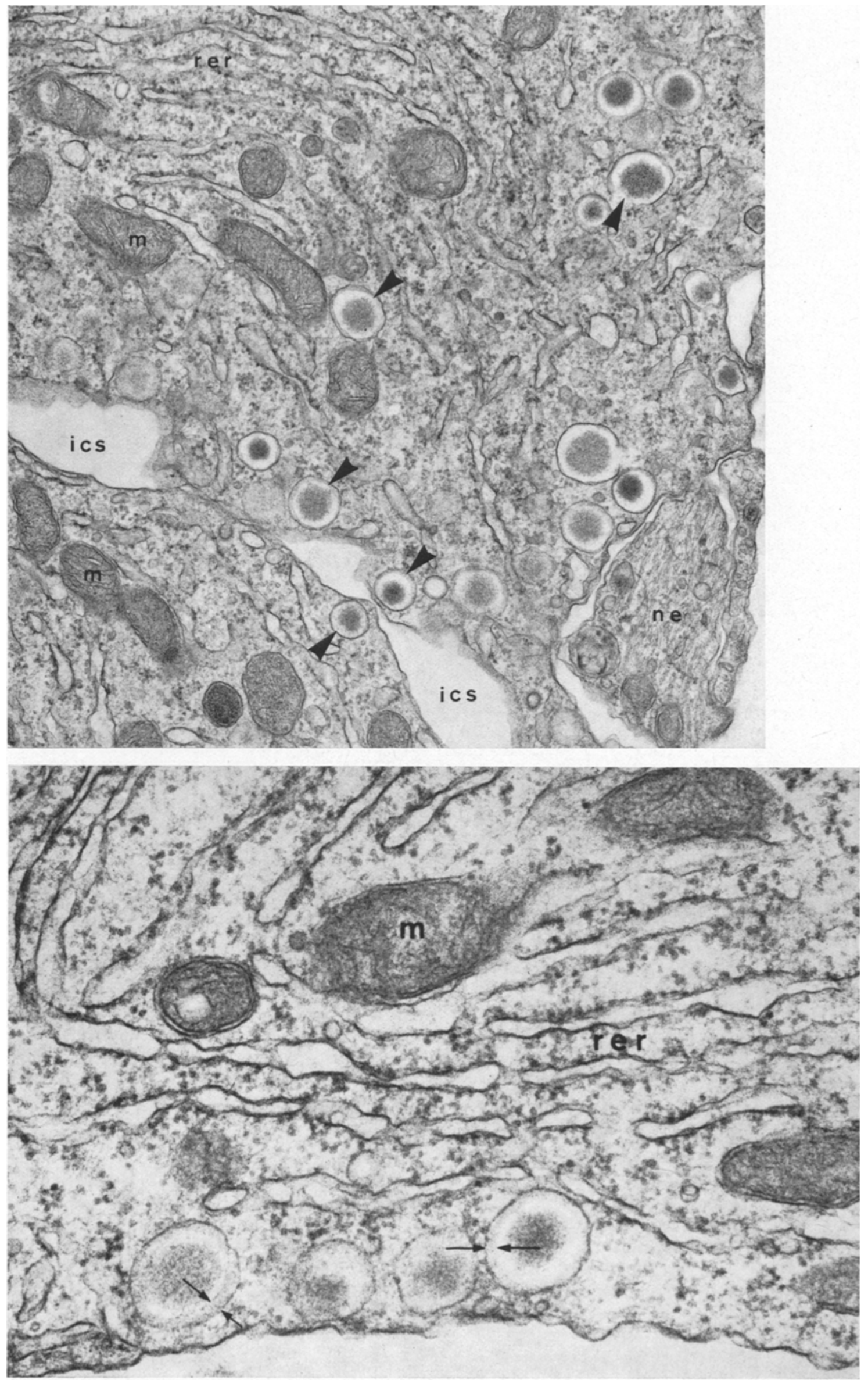

Fig. 12 


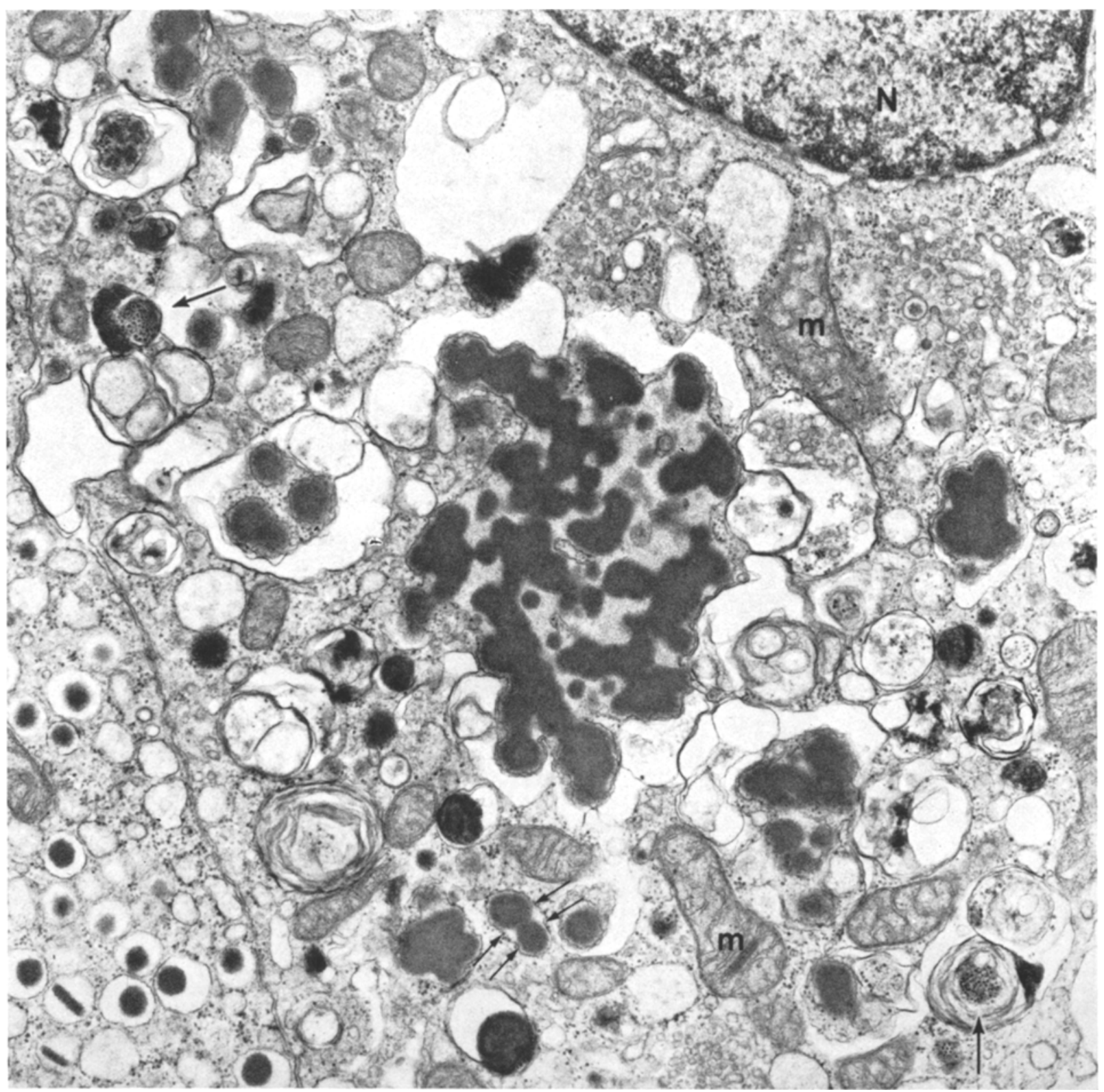

Fig. 13

Fig. 11. Beta cells, hamster, erratic type diabetes. Secretory storage granules (arrow heads) are diminished, variable in size and electron-density, and frequently situated at the plasma membrane. rer =rough endoplasmic reticulum, $m=$ mitochondria, ne=nerve ending, ics=intercellular space. Approximately $33,000 \times$

Fig. 12. Beta cell with secretory granules "marginated" at the plasma membrane. The granule cores are indistinct and a rim of fine particulate material appears to be layered upon the inner surface of the granule limiting membrane (arrows). Rough endoplasmic reticulum (rer) is increased. Approximately $62,400 \times$

Fig. 13. Beta cell, non-ketotic hamster, showing evidence of cytoplasmic degeneration. Large and small aggregates of membrane bound electron-dense material occupy a large area of cell cytoplasm. Membrane surrounding small aggregates appears studded with ribosomes (paired arrows). Elsewhere glycogen particles are visible (single arrows). Cytoplasmic discontinuity and myelin figures are also present. Approximately $24,500 \times$ 


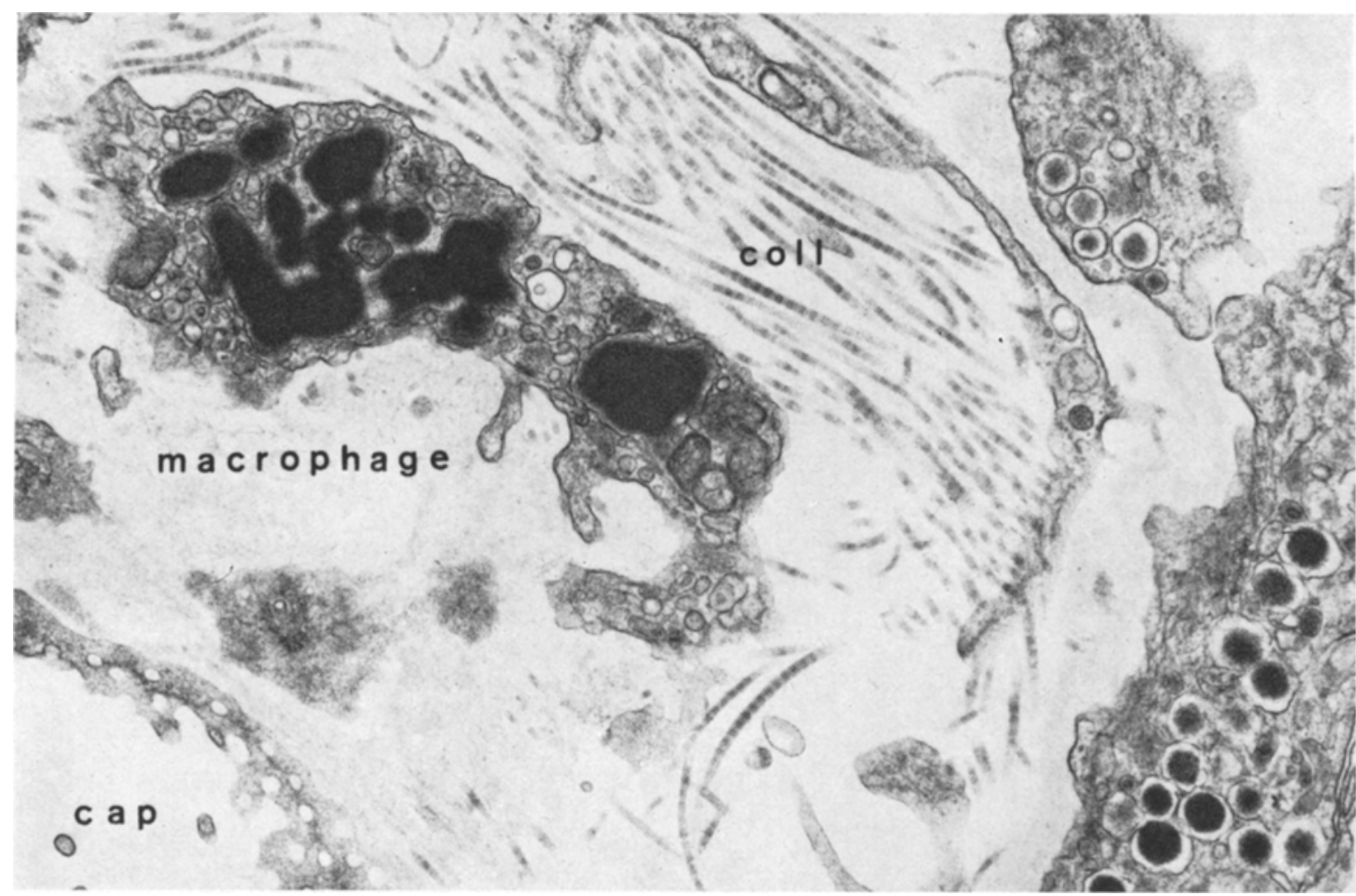

Fig. 14. Macrophage containing electron-dense cellular debris from necrotic beta cell is external to an islet capillary. Collagen fibrils (coll) are abundant in this focus of islet fibrosis. Hamster with erratic type diabetes. Approximately $28,600 \times$

Finally, it must be reemphasized that many of the fundamental observations of earlier workers $[2,3,4]$ concerning the ultrastructural alterations of the pancreatic islets of the severely diabetic Chinese hamsters have been confirmed.

Acknowledgements. The authors wish to acknowledge with appreciation the skillful technical assistance of Mr. Douglas Hylan and Mr. Kenneth Andrews.

\section{References}

1. Like, A.A., Gerritsen, G.C., Dulin, W.E.: Studies in the diabetic hamster: Light microscopy and autoradiography of pancreatic islets. Diabetologia 10, $501-508(1974)$

2. Luse, S. A., Caramia, F., Gerritsen, G.C., Dulin, W.E.: Spontaneous diabetes mellitus in the Chinese hamster: An electron microscopic study of the islets of Langerhans. Diabetologia 3, 97-108 (1967)

3. Boquist, L.: Pancreatic islet morphology in diabetic Chinese hamsters. A light and electron microscopic study. Acta path. microbiol. scand. 75, 399-414 (1969)

4. Orci, L., Stauffacher, W., Dulin, W.E., Renold, A.E., Rouiller, Ch.: Ultrastructural changes in A-cells exposed to diabetic hyperglycemia. Observations made on pancreas of Chinese hamsters. Diabetologia $6,199-206(1970)$

5. Like, A.A., Orci, L.: Embryogenesis of the human pancreatic islets: A light and electron microscopic study. Diabetes 21, (Suppl. 2) $511-534$ (1972)

6. Björkman, N., Hellerström, C., Hellman, B.: The ultrastructure of the islets of Langerhans in normal and obese-hyperglycemic mice. Z. Zellforsch. 58, 803$819(1963)$
7. Like, A.A., Chick, W.L.: Studies in the diabetic mutant mouse. II. Electron microscopy of pancreatic islets. Diabetologia 6, 216-242 (1970)

8. Like, A.A., Miki, E.: Diabetic syndrome in sand rats. IV. Morphologic changes in islet tissue. Diabetologia 3, 143-166 (1967)

9. Like, A.A., Chick, W.L. : Pancreatic beta cell replication induced by glucocorticoids in subhuman primates. Amer. J. Path. 75, 329-348 (1974)

10. Logothetopoulos, J., Bell, E.G.: Histological and autoradiographic studies of the islets of mice injected with insulin antibody. Diabetes 15, 205 - 211 (1966)

11. Kern, H., Logothetopoulos, J. : Steroid diabetes in the Guinea pig. Studies on islet cell ultrastructure and regeneration. Diabetes 19, 145-154 (1970)

12. Frankel, B.J., Gerich, G.E., Fanska, R. E., Grodsky, G.M.: Subnormal insulin and excessive glucagon release from in vitro perfused pancreases of non-obese genetically diabetic Chinese hamsters. Diabetes 22, (Suppl. 1), 307 (1973)

13. Orci, L., Amherdt, M., Malaisse-Lagae, F., Perrelet, A., Dulin, W.E., Gerritsen, G.C., Malaisse, W.J., Renold, A.E. : Morphological characterization of membrane systems in $\mathrm{A}$ - and $\mathrm{B}$-cells of the Chinese hamster. Diabetologia 10, $529-539$ (1974)

14. Orei, L., Unger, R.H., Reynold, A.E.: Structural coupling between pancreatic islet cells. Experientia. (Basel) 29, 1015-1018 (1973)

Dr. A. A. Like

Elliott P. Joslin Research Laboratory

Joslin Diabetes Foundation, Inc.,

Dept. of Pathology

Peter Bent Brigham Hospital

Harvard Medical School

Boston, Mass.

USA 